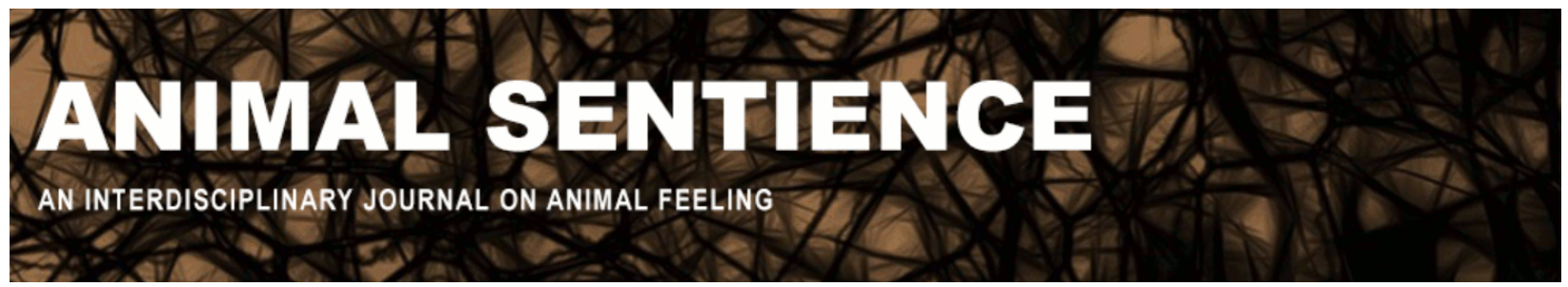

Clarke, Steve (2020) When some animals are more equal than others. Animal Sentience 29(33)

DOI: $10.51291 / 2377-7478.1625$

Date of submission: $2020-07-28$

Date of acceptance: 2020-08-02

(c)

This article has appeared in the journal Animal

Sentience, a peer-reviewed journal on animal

cognition and feeling. It has been made open access,

free for all, by WellBeing International and deposited

in the WBI Studies Repository. For more information,

please contact

wbisr-info@wellbeingintl.org.

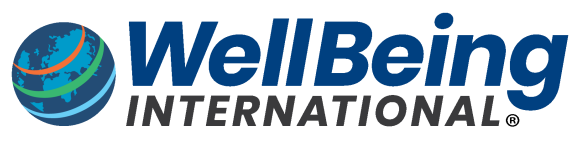

SOLUTIONS FOR PEOPLE, ANIMALS AND ENVIRONMENT 


\title{
When some animals are more equal than others
}

Commentary on Mikhalevich \& Powell on Invertebrate Minds

\author{
Steve Clarke \\ School of Humanities and Social Sciences, Charles Sturt University
}

\begin{abstract}
Mikhalevich \& Powell (2020) argue that we should attribute moral standing not only to vertebrates but also to certain invertebrates. M\&P also object on ethical grounds to policies of scientific funding agencies that encourage scientists to replace vertebrates by invertebrates in research. M\&P do allow that some invertebrates with brains may have lower levels of moral status than some vertebrates, but this seems to conflict with their case against replacement policies.
\end{abstract}

\begin{abstract}
Steve Clarke is an Associate Professor of Philosophy in the School of Humanities and Social Sciences at Charles Sturt University, Australia and Senior Research Associate in the Wellcome Centre for Ethics and Humanities, and the Uehiro Centre for Practical Ethics, Faculty of Philosophy, at the University of Oxford. Website
\end{abstract}

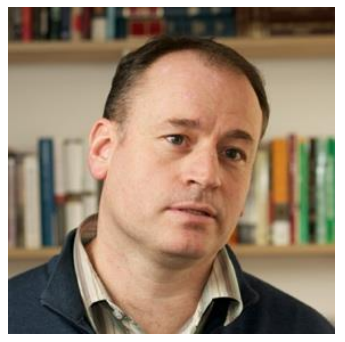

Mikhalevich \& Powell (2020) (M\&P) make the case for attributing moral standing to invertebrates with brains, alongside vertebrates. One of their motivations is to oppose policies of scientific funding agencies that encourage scientists to replace vertebrates with invertebrates in research, where possible, on ethical grounds. M\&P note, approvingly, that some regulatory bodies now discourage experimentation on cephalopod molluscs, such as octopus, squid and cuttlefish. But they regard policies that treat a few species of invertebrates as 'honorary vertebrates' as not going far enough - although they do not advocate going as far as some Jain monks, who "sweep the floor before them ... to avoid stepping on scurrying ants and beetles".

Why are M\&P reconciled to the prospect of some invertebrates, to whom they attribute moral standing, continuing to being stepped on by humans, and thereby killed or maimed? One reason they suggest, following McMahan (2002), is that death may not constitute a harm for animals that lack an interest in a valuable future. But ants and beetles do not always die immediately after being stepped on. In some cases they may suffer for a period of time before dying, or they may survive, but with physical impairments that reduce their welfare. M\&P address such concerns by suggesting that although some invertebrates with brains have moral standing, they do not share the same level of moral status as vertebrates. M\&P suggest that we humans need not be expected to "shoulder unpalatable moral burdens" in "drastically altering our lifeways" when we attribute low levels of moral status to ants and beetles. The moral status of mice and hamsters is presumably high enough to justify the moral demand to avoid stepping on them, but the moral status of ants and beetles is not.

Although the appeal to different levels of moral status addresses the 'Jain monk problem', it appears to conflict with M\&P's case against vertebrate replacement policies in research. 
Consider a simple hypothetical rescue scenario on the way we typically respond to the competing interests of beings with differing levels of moral status: We can save either a drowning human with 'full moral status' or a drowning chimpanzee with a lower level of moral status, but not both. There is overwhelming agreement that we should save the human and allow the chimpanzee to die in this scenario. If our reason was that we accord partial moral status to the chimpanzee -- say, $18 \%$, compared to $100 \%$ for the human -- then in a choice between saving one human or six chimpanzees, we would save the six chimpanzees (108\%). But most of us would not sacrifice the life of a human to save six, sixty or even six hundred chimpanzees.

We don't usually try to weigh the competing interests of beings with different levels of moral status as M\&P seem to think. More typically, we treat the interests of beings with higher levels of moral status as trumping the interests of those with lower levels. This is not just anthropocentrism. We would be unlikely to sacrifice the welfare of one chimpanzee to prevent harm to six, sixty or six hundred ants. We also presume that hypothetical beings who regarded their moral status as higher than ours would regard them as trumping ours. (Agar (2013) and other philosophers have urged us not to try to create cognitively enhanced "post humans" who may come to regard themselves as having higher moral status than humans.)

M\&P's suggestion that many invertebrates do have some level of moral status, but lower than that of many vertebrates, is plausible. But to oppose policies replacing vertebrates with invertebrates in research M\&P would need to show why it is wrong to let the interests of beings with higher moral status trump those of beings with lower moral status.

\section{References}

Agar, Nicolas (2013) Why it is possible to enhance moral status and why doing so is wrong. Journal of Medical Ethics, 39, 67-74.

McMahan, Jeff (2002) The ethics of killing: Problems at the margins of life. Oxford University Press.

Mikhalevich, Irina \& Powell, Russell (2020) Minds without spines: Evolutionarily inclusive animal ethics, Animal Sentience 29 (1). 